\title{
Clinical presentation and diagnosis of neuropathic pain
}

\author{
Quadro clínico e diagnóstico da dor neuropática \\ Guilherme Antônio Moreira de Barros ${ }^{1}$, Orlando Carlos Gomes Colhado², Mário Luiz Giublin ${ }^{3}$
}

DOI 10.5935/1806-0013.20160040

\section{ABSTRACT}

BACKGROUND AND OBJECTIVES: Neuropathic pain is reason for distress and incapacity of several patients, being that symptoms, mechanisms and management distinguish it from nociceptive pain. This study aimed at discussing the clinical presentation and diagnosis of neuropathic pain.

CONTENTS: Neuropathic pain is manifested by several symptoms, being continuous burning pain, shock sensation and mechanical alodynia the most common ones. Neurophysiologic studies and skin biopsy suggest that burning pain is reflex of spontaneous activity of afferent nociceptive fibers, while shock sensation is originated from high frequency ectopic stimuli, generated in demyelinated $A \beta$ fibers. Clinical exam, made up of history and elementary physical neurological evaluation, is critical for the adequate diagnosis of the type of pain, as well as more detailed exams, such as quantitative sensory tests and confocal optic microscopy, may bring further subsidies to the diagnosis of the type of pain.

CONCLUSION: Clinical presentation of neuropathic pain has characteristics which help the accurate diagnosis of the syndrome or disease responsible for the onset of the complaint. Adequate clinical evaluation, including directed physical neurologic exam, sensory quantitative tests and cornea confocal microscopy cooperate for a more accurate diagnosis.

Keywords: Clinical presentation, Diagnosis, Neuropathic pain.

\section{RESUMO}

JUSTIFICATIVA E OBJETIVOS: A dor neuropática é motivo de sofrimento e incapacidade para muitos pacientes, sendo que os seus sintomas, mecanismos e tratamento a distinguem da dor nociceptiva. O objetivo deste estudo foi discutir o quadro clínico e o diagnóstico da dor neuropática.

CONTEÚDO: A dor neuropática se manifesta por meio de vários sintomas, sendo os mais comuns a dor contínua em queimação, sensação de choque e alodínea mecânica. Estudos neurofisiológicos e biópsia de pele sugerem que dor em queimação é reflexo de atividade espontânea em fibras nociceptivas aferentes, enquanto a sensaçấo de choque presumidamente é originada de estímulos ectópicos de alta frequência, gerados em fibras $\mathrm{A} \beta$ desmielinizadas. $\mathrm{O}$ exame clínico, constituído por anamnese e exame físico neurológico elementar é de primordial importância para o adequado diagnóstico do tipo de dor. Assim como exames mais minuciosos, como os testes sensoriais quantitativos e a microscopia ótica confocal, podem trazer subsídios mais aprofundados ao diagnóstico do tipo de dor.

CONCLUSÁO: O quadro clínico da dor neuropática possui características que auxiliam no correto diagnóstico da síndrome ou doença que seja a responsável pelo aparecimento da queixa. Adequado exame clínico, incluindo a realização de exame físico neurológico dirigido, juntamente com os testes quantitativos sensoriais e com o exame de microscopia confocal de córnea colaboram para a execução mais precisa do diagnóstico.

Descritores: Diagnóstico, Dor neuropática, Quadro clínico.

1. Universidade Estadual Paulista, Faculdade de Medicina de Botucatu, Botucatu, SP, Brasil. 2. Universidade Estadual de Maringá, Faculdade de Medicina, Maringá, PR, Brasil.

3. Universidade Federal do Paraná, Clínica de Dor, Curitiba, PR, Brasil.

Conflict of interests: none - Sponsoring sources: none.

Correspondence to:

Guilherme Antônio Moreira de Barros

Departamento de Anestesiologia da FMB - UNESP

Caixa Postal 530 - Distrito de Rubiáo Jr

18618-687 Botucatu, SP, Brasil.

E-mail: barros@fmb.unesp.br

(C) Sociedade Brasileira para o Estudo da Dor

\section{INTRODUCTION}

Neuropathic pain (NP) is reason for distress and incapacity for many patients, being a public health problem. So, all physicians should know how to diagnose it. Its symptoms, mechanisms and management make it different from nociceptive pain, reason why its accurate diagnosis is important for the institution of adequate management ${ }^{1}$. This study aimed at discussing NP clinical presentation as well as clinical exams. Sensory quantitative test and corneal confocal optic microscopy will be briefly addressed. The discussion of other diagnostic methods, including elecrophysiologic studies and the use of standardized questionnaires are covered by other sections of this publication.

\section{CONCEPT OF NEUROPATHIC PAIN}

Pain induced by injury or disease affecting afferent somatosensory pathways, manifested through different symptoms, being the most common continuous burning pain, pain in electric shock and mechanical allodynia $^{2}$.

\section{ELEMENTARY NEUROPATHIC PAIN NEUROANATOMY}

Poorly myelinated $\mathrm{A} \delta$ fibers and unmyelinated $\mathrm{C}$ fibers, which are commonly called small fibers, make up a heterogeneous population with different functions and subtypes. Some of these fibers have autonomic functions, such as sweating and blood pressure regulation and, additionally, they transport sensations such as temperature, pain, itching or touch. Small fibers cell bodies are located in dorsal root ganglia and their fibers end as nociceptors in the epidermis ${ }^{3}$.

Small fibers neuropathy, which courses with burning pain affecting toes and soles of the feet, is normally very severe and is followed by paresthesias and dysesthesias. The reason for small fibers pain is still not completely understood and the most probable hypothesis is a decrease in the number of peripheral nociceptors and also the fact that remaining small fibers are more susceptible to the influence of their medium, such as increased painful and pro-inflammatory cytokines ${ }^{3}$.

Nociceptive peripheral afferences carried by first order neurons enter spinal cord dorsal horn. Gelatinous substance, consisting of laminae I and II, receive messages from myelinated A $\delta$ fibers and unmyelinated $\mathrm{C}$ fibers (especially the latter). Lamina II interneurons and deeper laminae (III to $\mathrm{V})$ receive impulses carried by larger $\mathrm{A} \beta$-type myelinated fibers, which in normal situations do not transmit painful impulses. Primary afferent neuron terminals relieve excitatory neurotransmitters, such as glutamate and $\mathrm{P}$ substance and the calcitonin genetically related peptide (CGRP), to activate second order neurons in spinal cord dorsal horn ${ }^{4}$.

Laminae I and V neurons are projected along spinothalamic and squamous thalamic reticulum pathways and are sent to supraspinal structures, such as brainstem, thalamus, somatonsensy cortex, insular cortex and anterior singular cortex. Integrative studies show strong evidences that NP is largely a consequence of persistent plastic changes along sensory pathways ${ }^{4}$.

After traveling through the spinal cord, nociceptive information reaches supra-segmental nervous structures in bulb, midbrain and diencephalon with which they may synapse or end there. Among such structures there are thalamus reticular formation, hypothalamus, limbic system and brain cortex. The role of these supraspinal systems in pain pathophysiology is not clearly known. Probably different regions are involved in sensory and affective understanding of the painful phenomenon ${ }^{5}$.

Encephalic responses to nociception may be more easily understood than allodynia, for example. Allodynia is a severe pain induced by normally painless stimuli, such as touch or thermal stimuli experienced by NP 
patients. Allodynia is associated to abnormal increase of SII area in anterior insular cortex, contralateral and ipsilateral to the painful area. Since increased bilateral brain activity has been repeatedly observed in painful conditions such as allodynia, this would explain why painless physiologic stimuli could be perceived as painful in patients with damaged nervous system $^{6}$.

Both secondary somatosensory system and insular cortex receive information from the thalamus, which is the largest relay of spinothalamic and sensory pathways, being this phenomenon critical for NP development. Both thalamic function and structure have been reported as abnormal, or impaired, even in baseline NP states. This fact may explain the spontaneous component of this pain. Additional studies are needed to prove the contribution of such areas to pathological processes and to better understand abnormalities related to pain and disaffection and, in the future, encourage further studies ${ }^{6}$.

\section{NEUROPATHIC PAIN CHARACTERISTICS}

NP is manifested by several symptoms, being the most common burning continuous pain, electric shock sensation and mechanical allodynia. Neurophysiologic studies and skin biopsy suggest that burning pain is reflex of the spontaneous activity of afferent nociceptive fibers, while electric shock sensation is presumably originated from ectopic high frequency stimuli, generated in unmyelinated $A \beta$ fibers. Mechanisms involved in mechanical allodynia genesis are still not totally explained; however it is known that harmless stimuli may induce pain by stimulating sensitized afferent fibers ${ }^{2}$.

NP may be classified as spontaneous (burning and pressing) or provoked (tugging and shock) by means of skin brushing, by pressure and by thermal stimuli, such as cold. Hyperalgesia, increased response to a normally painful stimulus, may be frequently observed. NP patients also complain of paresthesia and dysesthesia such as tingling, tugging and pricking ${ }^{2}$. A simple questionnaire filled by patients or by the examiner may be used to call the attention of the physician to the need for a careful evaluation of NP patients (Table 1) ${ }^{7}$. This subject, as already described, will be deeply addressed in another text of this same publication.

Table 1. Sensory changes found in neuropathic pain patients ${ }^{7}$

\begin{tabular}{lccc}
\hline Quantitative & Qualitative & Spatial & Temporal \\
\hline Hypoesthesia & Allodynia & Poor location & Abnormal latency \\
Hyperesthesia & Paresthesia & Abnormal irradiation & After stimulation \\
Hypoalgesia & Dysesthesia & & Summation \\
Hyperalgesia & & & \\
\hline
\end{tabular}

OBJECTIVE AND GENERAL PRINCIPLES OF THE EVALUATION OF PAINFUL PATIENTS ${ }^{1}$

Objectives of painful patients evaluation are: to identify pain pathophysiologic type, whether nociceptive, neuropathic or mixed, or none of them; to diagnose the disease or the event inducing pain; and to recognize functional limitation, possible associated comorbidities and other relevant aspects. The final objective of the evaluation is to better plan patients' care and management.

\section{Clinical exam}

It is important that patients describe their painful experience they way they understand it and self-report should be encouraged. History should gather data on location, temporal profile, intensity, improvement or worsening factors and simultaneous symptoms. One should ask about previous medical history, identify the presence of past and current diseases, previous surgeries, previous treatments for pain control and the results of such interventions. It is interesting to document the functional history, such as interference of symptoms on mobility, daily activities, interpersonal relations, as well as on sleep and mood.

\section{Anamnesis}

One should first listen to patients' history, avoiding interferences and encouraging them to describe their complaints and their understanding about causal factors of their pain.

After this first approach, one should specifically ask about signs and symptoms indicative of NP, taking into consideration that patients may not value or may over-value factors which are more or less important, depending on their point of view.

Professionals should ask objective questions, according to their knowledge, to get answers for the diagnosis of pain pathyphysiology, anatomy, classification and etiology, always considering that NP most of the times has late onset with regard to its cause. So, the difficulty in evidencing a physical-organic justification for the presence of pain does not mean that pain does not exist.

\section{Physical evaluation ${ }^{1}$}

Sometimes there might be discrepancy between patients' complaint and physical evaluation findings being necessary in some cases to repeat the tests. For a general evaluation, painful area is inspected and palpated. A thorough evaluation of cranial nerves, of motor function, of tendon reflexes, of muscle tone, of walking pattern and balance is carried out in sequence.

Sensory evaluation is the most important part of physical evaluation in case of suspicion of NP. As part of minimum recommended neurological exams, one should smoothly apply a cotton ball on the skin (tactile sensitivity), apply stimuli with sharp materials such as needles (painful sensitivity), thermal sensation by means of warm or cold objects (thermal sensitivity) and $128 \mathrm{~Hz}$ vibrations sensation by means of diapason. It is important to compare the side affected by pain to the same contralateral area when pain is unilateral and when pain is bilateral, comparison evaluation should be proximal and distal to pain.

The relationship between stimulus and perception may change quantitatively (hypo or hyper-phenomenon), qualitatively, spatially and temporally. Sensory losses should be specified with regard to involved sensory submodalities, such as tactile, painful and thermal. As example, allodynia evaluated with light pressure movements in a single point, harmless warm and cold to stimulate the injured area. The extension of body area affected by sensory changes should be always documented.

\section{Sensory quantitative tests}

Added to other ways to evaluate pain, sensory quantitative tests (SQT) may be extremely useful. These are noninvasive psychophysiologic tests to evaluate responses to a series of painful and painless stimuli. Differently from what happens with skin biopsy tests and with corneal confocal microscopy studies, their results express functional changes rather than possible anatomic injuries associated to them ${ }^{8}$.

SQTs go beyond neurological physical evaluation which traditionally evaluates somatosensory function. They provide a more precise evaluation of somatosensory changes in areas with changes determined by the sensory test ${ }^{9}$. An expressive number of studies evaluating procedures which allow the evaluation of any aspect of a certain sensory function has been already published, all of them directly based on patient's sensory experience report ${ }^{10}$.

Although potentially useful for NP diagnosis, the method has several limitations, being two of them of major practical importance. The first is the fact that there is no consensus or standardization of procedures, so any aspect of the sensory function may be evaluated by different ways. So, two measures of the same sensory function using the same tool in the same patient may result in different values due to variations on used parameters. The second limitation is the time needed for the application of the method, which in general goes beyond the time reserved by the physician for a routine consultation. In general, the test demands at least one hour to be applied, reason why there are proposals of standardized protocols with a limited number of tests ${ }^{8}$. Limitations are described in table 2 .

\section{Methods ${ }^{11}$}

In the last decades, the method made up of increasing and decreasing intensity stimuli has been enhanced. Patients respond to stimuli by pressing a button or informing verbally the physician when the stimulus is perceived or when it disappears. So, with serial application of stimuli, patients' threshold for a certain stimulus is determined. Stimuli may be continuously applied, which is called limit methods, or by means of a se- 
Table 2. Limitations of the quantitative sensory test ${ }^{1}$

\begin{tabular}{|c|c|}
\hline Limitations & Implications \\
\hline $\begin{array}{l}\text { Psychological approach; requi- } \\
\text { res active participation of pa- } \\
\text { tients (with risks of false-positi- } \\
\text { ves). }\end{array}$ & $\begin{array}{l}\text { Special relevance in cases of limited ver- } \\
\text { bal communication, impaired cognition, } \\
\text { severe psychiatric diseases, sleepiness } \\
\text { states due to tiredness or use of drugs } \\
\text { (e.g., benzodiazepines), simulation of di- } \\
\text { seases. }\end{array}$ \\
\hline $\begin{array}{l}\text { The test can only be performed } \\
\text { in a single body area and just } \\
\text { once. }\end{array}$ & $\begin{array}{l}\text { Choice of test area should be done after } \\
\text { clinical evaluation; if necessary, test se- } \\
\text { veral areas. }\end{array}$ \\
\hline $\begin{array}{l}\text { Limited sensitivity to detect } \\
\text { function loss in neuropathies } \\
\text { (risk of false-negatives) }\end{array}$ & $\begin{array}{l}\text { Examples: children with diabetes or in- } \\
\text { creased limbo-cortical representation; } \\
\text { sensitivity may be increased by bilate- } \\
\text { ral evaluation in systemic neuropathies } \\
\text { (comparison with contralateral area) and } \\
\text { when using face and upper limbs as con- } \\
\text { trol areas. }\end{array}$ \\
\hline $\begin{array}{l}\text { Only the evaluation of the com- } \\
\text { plete pathway is possible. }\end{array}$ & $\begin{array}{l}\text { There is no differentiation between the } \\
\text { origin of loss, or of hyperalgesia, betwe- } \\
\text { en peripheral and central (e.g., evaluate } \\
\text { face as control area in case of polyneuro- } \\
\text { pathy and lateral radiculopathy). }\end{array}$ \\
\hline $\begin{array}{l}\text { Limiting values are needed to } \\
\text { prevent skin injuries }\end{array}$ & $\begin{array}{l}\text { In some cases it is not possible to detect } \\
\text { minor changes due to the confidence } \\
\text { interval of } 95 \% \text { of healthy individuals be } \\
\text { close to limiting values used in the test. }\end{array}$ \\
\hline $\begin{array}{l}\text { Time needed for the application } \\
\text { (approximately one hour for two } \\
\text { areas) }\end{array}$ & $\begin{array}{l}\text { Possible problems with tiredness and } \\
\text { loss of concentration. }\end{array}$ \\
\hline $\begin{array}{l}\text { Contralateral area inadequate as } \\
\text { control }\end{array}$ & $\begin{array}{l}\text { In patients with systemic or bilateral dise- } \\
\text { ases, choose face or hand as control to } \\
\text { improve sensitivity and specificity. }\end{array}$ \\
\hline
\end{tabular}

ries of predefined stimuli, which is called levels method ${ }^{12}$. Negative qualities, such as hypoesthesia and hypoalgesia, in addition to positive such as allodynia, hyperalgesia and hyperesthesia are evaluated.

The German Research Network on Neuropathic Pain (DFNS) (http:// www.neuro.med.tu-muenchen.de/dfns/uns/e_portrait.html) was created in 2002 to promote the study and disclosure of NP mechanisms and treatments. Based on a national German database, phenotypic characteristics of different NP situations have been collected, including demographic, psychometric and clinical data. These data include results of QST tests, the parameters of which are shown in table $3^{13}$.
There are 13 different tests, including smaller and larger neurological fibers evaluation. In general, painful sensitivity is evaluated by mechanical stimuli (such as needle prick) or thermal stimuli with intensity above or below individual threshold. These stimuli are especially useful to evaluate positive signals, such as allodynia and hyperalgesia. Although there is correlation in some somatosensory aspects with specific QST tests, the evaluation of total sensory profile with the complete test is useful for better understanding possible mechanisms involved. As example, an abnormal threshold to cold may mean changes in A $\delta$ fibers, but if it is simultaneous with abnormal warmth sensation, it may be result of descending inhibitory system impairment.

To evaluate deep tissues, such as muscles and fascia, just pressure pain threshold (PPT) is used as parameter and is decreased in regional complex pain syndrome (RCPS), neurological injuries and peripheral neuropathy. The so-called wind up rate may be evaluated with the application of a single stimulus, followed by a series of stimuli to measure painful response to temporal summation, which would be indirectly correlated to posterior horn neurons phenomenon ${ }^{11}$.

\section{Validation and adaptation}

The application protocol of QST established by DFNS is already broadly used in European countries. Since recommended protocols were developed based on reference databases, there are already parameters according to gender, age group and affected body areas for a certain patient. It is also possible to compare in the same individual two different sides, which is particularly useful in unilateral affection situation. The use of specific software helps data interpretation, also allowing the comparison of the exam performed in different moments by different examiners ${ }^{11}$.

\section{Clinical use}

QST may be used to detect small fibers impairment, such as unmyelinated C fibers and poorly myelinated A $\delta$ fibers. These clinical situations in general are followed by dysesthesias or paresthesias with normal nervous conduction studies, such as electroneuromyography. These changes may be early signs of neuropathy different from peripheral neuropathy, identified by changes in thermal threshold which is increased and has sensitivity of $36-85 \%$ as compared to skin biopsies ${ }^{14}$.

It is known that the same disease, or the same type of NP, have different sensory profiles in different patients. So, a classification based on QST findings was proposed, to differentiate normal sensory aspects (L0G0) from hypoesthesia to thermal stimuli (L1), to mechanical stimuli (L2) or to both (L3); or hyperalgesia to thermal stimuli (G1), to mechanical stimuli (G2) or to both (G3) ${ }^{13}$.

QST has been of diagnostic value in several situations, among them diabetes, even in asymptomatic patients to differentiate types of CRPS, peripheral nervous injury, Fabry disease, spinal cord trauma, and fibromy-

Table 3. Modality, receptors and methods of the quantitative sensory test (QST) ${ }^{11}$

\begin{tabular}{|c|c|c|c|c|c|}
\hline Stimuli & DFNS protocol & Device & Type of axon & CNS pathway & Hyperalgesia/allodynia mechanism \\
\hline \multicolumn{6}{|l|}{ Thermal } \\
\hline Cold & CDT & Computerized thermometer & A $\delta$ & Spinothalamic & - \\
\hline Painful cold & CPT & & $\mathrm{A} \delta, \mathrm{C}$ & Spinothalamic & $\begin{array}{c}\text { Central and peripheral sensitizations, } \\
\text { decreased inhibition }\end{array}$ \\
\hline Painful warmth & HPT & & $A \delta, C$ & Spinothalamic & Peripheral sensitization \\
\hline Static puncture (blunt tip) & MDT & Von Frey filaments & $A \beta$ & Lemniscal & - \\
\hline Vibration & VDT & Gauged diapason & $A \beta$ & Lemniscal & Unknown \\
\hline Skin puncture (acute tip) & MPT, MPS & Gauged metal needles & $A \delta, C$ & Spinothalamic & Central sensitization \\
\hline Blunt pressure & PPT & Pressure algometer & $A \delta, C$ & Spinothalamic & Unknown \\
\hline Dynamic mechanical & DMA & $\begin{array}{l}\text { Brush, cotton Ball, cotton } \\
\text { swab }\end{array}$ & $\mathrm{A} \delta, \mathrm{C}$ & Lemniscal & Central sensitization \\
\hline
\end{tabular}


algia, among others. Other indication that will be useful in the future is monitoring the response to topic treatment with lidocaine or capsaicin, as well as the indication of treatment according to pain phenotypic profile ${ }^{11}$.

\section{NEUROPHYSIOLOGY}

Neurophysiological techniques, such as studies of nervous conduction, trigeminal reflexes and somatosensory evoked potential are mediated by non-nociceptive large afferent $A \beta$ fibers and are widely used to evaluate central and peripheral nervous system diseases ${ }^{15}$. Such techniques are useful to show the location and to quantify peripheral and central somatosensory pathway changes.

Most clinical and experimental studies show that NP is induced by nociceptive conduction injury and so the results of non-nociceptive fibers do not contribute to the diagnosis ${ }^{15}$.

Recent studies, however, have suggested that some specific NP types are specifically associated to $A \beta$ fibers injury. Patients with peripheral and central nervous system diseases with sensations of electric shock in paroxysm are associated to abnormal neurophysiologic responses mediated by non-nociceptive $A \beta$ fibers $^{16}$.

\section{CORNEAL CONFOCAL MICROSCOPY}

The eye is the only human organ allowing the inspection of central and peripheral nerves at one time. Cornea is densely innervated by the ophthalmic branch of the trigeminal nerve. Corneal innervations may be divided in three structures: subepithelial plexus, stromal nerves and subbasal plexus, which is located between the basal epithelium and Bowman membrane, being parallel to eye surface and made up of small nervous fibers with thickness of 0.2 to $10 \mu \mathrm{m}^{17,18}$. Corneal nerves are $A \delta$ fibers or $\mathrm{C}$ fibers with polymodal receptors with low threshold to nociception and mechanical and cold stimuli.

\section{Methods}

To perform corneal confocal microscopy (CCM) the eye is prepared with local anesthetics and hypromellose. The microscope is placed on central cornea and connected to a tomograph, allowing high resolution pictures of the sub-basal nerve plexus. The analysis of the images with the best representation of corneal nervous fibers may be done manually or by means of a software ${ }^{19}$.

Analyzed parameters are: (a) corneal nervous fibers length (NFL), defined as the absolute length of branches and nerves in $\mathrm{mm}^{2}$ (being considered normal the measure of $18 \mathrm{~mm}^{2}$, with variation between $11-14 \mathrm{~mm} / \mathrm{mm}^{2}$; (b) nervous fiber density (NFD), defined as the total number of larger nerves by $\mathrm{mm}^{2}$ (being considered normal the number of 42 [31-54]; and (c) nervous fibers branches (NFB), defined as the number of branches per $\mathrm{mm}^{2}$ (normal 35 [25-55]). NFL is the most practical parameter, but NFD is the best parameter to diagnose NP by $\mathrm{CCM}^{20,21}$.

\section{Clinical application}

CCM has been primarily used to diagnose diabetic polyneuropathy and sarcoidosis, being that data of its application for other diseases are scarce. A recent metanalysis of 13 studies with 1680 participants has confirmed its value to early detect nervous changes in patients with diabetic neuropathy. Curiously, patients with intolerance to glucose already show evidences of neuropathy detectable by CCM. In addition, patients with intolerance to glucose, who later developed diabetes type 2, had significantly lower NFD, NFL and NFB as compared to the control group. Additionally, CCM detects minor nervous fibers injuries, even in the absence of other complications of the disease, such as retinopathy or microalbuminuria in patients with diabetes type $1^{22}$. So, CCM may help the identification of patients at risk and who need a more rigorous treatment regimen. The correlation between corneal nervous fibers loss and severity of diabetic polyneuropathy has been identified ${ }^{23}$.

Currently, many other diseases are being investigated with CCM, such as chronic migraine, Wilson disease, chronic inflammatory unmyelinating polyneuropathy and amyotrophyc lateral sclerosis where signs of neuropathy are detected by CCM. As compared to other tools, diagnostic efficacy of CCM is comparable or even better than the quantification of intraepidermal nervous fibers (IENF) but has not been compared to QST in larger cohorts. The finding of normative values of healthy volunteers is a step further to allow the widespread clinical use of this technique ${ }^{24}$.

A major advantage of CCM seems to be that corneal nerves density is more dynamically changed after treatment than skin innervations or nervous function measured by QST. Similarly, significant pain relief and partial corneal NFL and NFD normalization were reported after sarcoidosis treatment with ARA 290, a peptide with 11 aminoacids obtained as from the erythropoietin structure ${ }^{25}$.

So, CCM is a limited method for routine use due to high costs of equipment acquisition and availability, currently restricted to research centers. However, this is a promising and well tolerated tool to detect the loss of small nervous fibers in early stages of systemic diseases and to monitor recovery after treatment. The comparison with established methods, such as skin biopsy and QST in different diseases is needed for the validation of this method.

\section{SKIN BIOPSY}

This is a minimally invasive tool to investigate nociceptive fibers in human dermis and epidermis. Researchers have used this technique to quantitatively and qualitatively evaluate IENF. Skin biopsy (SB) may be performed anywhere in the body with a punch needle under local anesthesia. To diagnose peripheral neuropathy, SB is commonly performed on the leg at a distance of $10 \mathrm{~cm}$ above lateral malleolus and a more proximal $\mathrm{SB}$ on the thigh, approximately $20 \mathrm{~cm}$ below iliac spine. So, proximal and distal samples may be used to help diagnosing neuropathic disease ${ }^{26}$.

Morphometric analysis in SB is possible when using the antibody 9.5 against cytoplasm protein gene product (PGP) ${ }^{27}$. PGP 9.5 is broadly distributed in the peripheral nervous system and is a nonspecific panaxonal marker. SB has been used to investigate the density of intradermal fibers in peripheral nerve diseases, such as diabetic neuropathy, infectious and inflammatory neuropathies associated to systemic diseases ${ }^{26,28}$. In all studies, IENF density was significantly lower in patients with neuropathies as compared to control individuals ${ }^{28}$.

Distal leg SB with quantification of intradermal small fibers density using established rules is considered an effective technique for the diagnosis of small fibers neuropathy ${ }^{29,30}$. With SB it was possible to detect evidences of small fibers neuropathy in a variety of conditions ${ }^{31}$, including fibromyalgia patients $\mathrm{s}^{32,33}$. So, SB has been recommended as important part of diagnostic tests for small fibers neuropathy in fibromyalgia patients ${ }^{34}$.

\section{CONCLUSION}

NP has clinical presentation and result of simple physic neurologic evaluation at bedside, which helps its diagnosis. However, additional methods, such as QST, CCM and SB are significant contributors to the accuracy of the diagnosis. NP treatment is different from that of nociceptive pain and for this reason its accurate diagnosis is important to establish the treatment. It is worth reminding that, as with any other symptom, NP is present in a significant number of diseases and so specific treatments for the underlying cause should be available.

\section{REFERENCES}

1. Haanpää M. Clinical Examination of a Patient with Possible Neuropathic Pain. In: Raja S vSC, edito Pain 2014 Refresher Courses - 15 th World Congress on Pain. Washington: IASP Press; 2014. 201-6p. Truini A, Cruccu G. How diagnostic tests help to disentangle the mechanisms underlying neuropathic pain symptoms in painful neuropathies. Pain. 2016;157(2 Suppl1):S53-8.

Üçeyler N. Small fiber pathology - a culprit for many painful disorders? Pain. 2016;157(2Supp1):S60-6.

4. Zhuo M, Wu G, Wu LJ. Neuronal and microglial mechanisms of neuropathic pain. Mol Brain 2011;4:31.

Ossipov MH. The perception and endogenous modulation of pain. Scientifica. 2012;2012:1-12.

6. Peyron R. Functional brain imaging what has it brought to our understanding of neuropathic pain?

A special focus on allodynic pain mechanisms. Pain. 2016;(2 Supp1):S67-71.
Bennett MI, Bouhassira D. Epidemiology of neuropathic pain: can we use the screening tools? Pain. Bennett MI, Bouhassita

8. Rolke R, Magerl W, Campbell KA, Schalber C, Caspari S, Birklein F, et al. Quantitative sensory testing: a comprehensive protocol for clinical trials. Eur J Pain. 2006;10(1):77-88.

9. Backonja MM, Attal N, Baron R, Bouhassira D, Drangholt M, Dyck PJ, et al. Value of quantitative sensory testing in neurological and pain disorders: NeuPSIG consensus. Pain. 2013;154(9):1807-19.

10. Greenspan JD. Quantitative assessment of neuropathic pain. Current pain and headache reports. 2001;5(2):107-13.

11. Maier C KE, Mainka T, Schargus M. Quantitative Sensory Testing an Confocal Microscopy: Indications, Methodology, Interpretation, and Pitfalls. In: Raja SN SC, editor. Pain 2014 Refresher 
Courses - 15th World Congress on Pain. Washington: IASP Press; 2014. 207-16p.

12. Walk D, Sehgal N, Moeller-Bertram T, Edwards RR, Wasan A, Wallace M, et al. Quantitative sensory testing and mapping a review of nonautomated quantitative methods for examination of the patient with neuropathic pain. Clin J Pain. 2009;25(7):632-40.

13. Maier C, Baron R, Tolle TR, Binder A, Birbaumer N, Birklein F, et al. Quantitative sensory testing in the German Research Network on Neuropathic Pain (DFNS): Somatosensory abnormalities in 1236 patients with different neuropathic pain syndromes. Pain. 2010;150(3):439-50.

14. Nebuchennykh M, Loseth S, Lindal S, Mellgren SI. The value of skin biopsy with recording of intraepidermal nerve fiber density and quantitative sensory testing in the assessment of small fiber involvement in patients with different causes of polyneuropathy. J Neurol. 2009;256(7):1067-75.

15. Garcia-Larrea L. Objective pain diagnostics: clinical neurophysiology. Neurophysiol Clin. 2012;42(4):187-97.

16. Truini A, Galeotti F, La Cesa S, Di Rezze S, Biasiotta A, Di Stefano G, et al. Mechanisms of pain in multiple sclerosis: a combined clinical and neurophysiological study. Pain. 2012;153(10):2048-54.

17. Al-Aqaba MA, Alomar T, Miri A, Fares U, Otri AM, Dua HS. Ex vivo confocal microscopy of human corneal nerves. Br J Ophthalmol. 2010;94(9):1251-7.

18. Al-Aqaba MA, Fares U, Suleman H, Lowe J, Dua HS. Architecture and distribution of human corneal nerves. Br J Ophthalmol. 2010;94(6):784-9.

19. Stave J, Zinser G, Grummer G, Guthoff R. [Modified heidelberg reginal tomograph HRT. Initial results in vivo presentation of corneal structures]. Ophthalmologe. 2002;99(4):276-80. German.

20. Ahmed A, Bril V, Orszag A, Paulson J, Yeung E, Ngo M, et al. Detection of diabetic sensorimotor polyneuropathy by corneal confocal microscopy in type 1 diabetes a concurrent validity study. Diabetes Care, 2012;35(4):821-8.

21. Papanas N, Ziegler D. Corneal confocal microscopy: a new technique for early detection of diabetic neuropathy. Curr Diab Rep. 2013;13(4):488-99.

22. Petropoulos IN, Green P, Chan AW, Alam U, Fadavi H, Marshall A, et al. Corneal confocal microscopy detects neuropathy in patients with type 1 diabetes without retinopathy or microalbuminuria. PLoS One. 2015;10(4):e0123517.

23. Petropoulos IN, Alam U, Fadavi H, Asghar O, Green P, Ponirakis G, et al. Corneal nerve loss detected with corneal confocal microscopy is symmetrical and related to the severity of diabetic polyneuropathy. Diabetes Care. 2013;36(11):3646-51.

24. Tavakoli M, Ferdousi M, Petropoulos IN, Morris J, Pritchard N, Zhivov A, et al. Normative value for corneal nervemorphology assessed using corneal confocal microscopy: a multinational normative data set. Diabetes Care. 2015;38(5):838-43.

25. Heij L, Niesters M, Swartjes M, Hoitsma E, Drent M, Dunne A, et al. Safety and efficacy of ARA 290 in sarcoidosis patients with symptoms of small fiber neuropathy: a randomized, double-blind pilot study. Mol Med. 2012;18:1430-6.

26. Ebenezer GJ, Hauer P, Gibbons C, McArthur JC, Polydefkis M. Assessment of epidermal nerve fibers: A new diagnostic and predictive tool for peripheral neuropathies. J Neuropathol Exp Neurol. 2007;66(12):1059-73.

27. Wang L, Hilliges M, Jernberg T, Wiegleb-Edstrom D, Johansson O. Protein gene-product 9.5-immunoreactive nerve-fibers and cells in human skin. Cell Tissue Res. 1990;261(1):25-33.

28. Lauria G, Hsieh ST, Johansson O, Kennedy WR, Leger JM, Mellgren SI, et al. European Federation of Neurological Societies/Peripheral Nerve Society Guideline on the use of skin biopsy in the diagnosis of small fiber neuropathy. Report of a joint task force of the European Federation of Neurological Societies and the Peripheral Nerve Society. Eur J Neurol. 2010;17(7):903-12, e44-9.

29. Kennedy WR, Nolano M, Wendelschafer-Crabb G, Johnson TL, Tamura E. A skin blister method to study epidermal nerves in peripheral nerve disease. Muscle Nerve. 1999;22(3):360-71.

30. Panoutsopoulou IG, Wendelschafer-Crabb G, Hodges JS, Kennedy WR. Skin blister and skin biopsy to quantify epidermal nerves: a comparative study. Neurology. 2009;72(14):1205-10.

31. Themistocleous AC, Ramirez JD, Serra J, Bennett DL. The clinical approach to small fibre neuropathy and painful channelopathy. Pract Neurol. 2014;14(6):368-79.

32. Uceyler N, Zeller D, Kahn AK, Kewenig S, Kittel-Schneider S, Schmid A, et al. Small fibre pathology in patients with fibromyalgia syndrome. Brain. 2013;136(Pt 6):1857-67.

33. Caro XJ, Winter EF. Evidence of abnormal epidermal nerve fiber density in fibromyalgia: clinical and immunologic implications. Arthritis Rheumatol. 2014;66(7):1945-54.

34. Levine TD, Saperstein DS. Routine use of punch biopsy to diagnose small fiber neuropathy in fibromyalgia patients. Clin Rheumatol. 2015;34(3):413-7. 